\title{
Corneal Reflex in Hemisphere Disease II
}

\author{
R. T. ROSS and J. A. JOHNSTON**
}

SUMMARY: In man, contralateral cerebral decortication or removal of a hemisphere does not permanently abolish the corneal reflex. Destruction of the contralateral thalamus or contralateral mesencephalic trigeminal tract does abolish the corneal reflex.

In the cat however, the corneal reflex remains intact after contralateral decortication, hemispherectomy and total ablation of the thalamus. Some of these procedures diminished the corneal reflex or increased the threshold, but neither of these changes were seen for more than a few days post-operatively. In this animal however, the second reflex response, evoked by supra orbital nerve stimulation, is abolished by certain thalamic lesions and by contralateral hemi-transection of the brain stem at various levels.

RÉSUMÉ: Chez l'humain, la décortication cérébrale contralatérale, ou l'ablation d'un hémisphère, n'abolissent pas de façon permanente le réflexe cornéen. Par contre, la destruction du thalamus contralatéral ou de la voie trigéminale mésencéphalique contralatérale abolit ce réflexe.

Cependant chez le chat, le réflexe cornéen reste intact même après la décortication contralatérale, l'hémispherectomie ou l'ablation totale du thalamus. Certaines de ces procédures ont en fait diminué le réflexe cornéen ou augmenté le seuil, mais ceci seulement pendant les quelques jours post-opération. Chez cet animal également, la seconde réponse réflexe, qui est induite par une stimulation du nerf supra-orbital, est abolie par certaines lésions thalamiques et par l'hemi-transection contralatérale du tronc cérébral à plusieurs niveaux.

From the section of Neurology, Department of Medicine, the University of Manitoba and the Winnipeg General Hospital.

**Present address - Department of Neurosurgery, University of Saskatchewan, Saskatoon.

*Reprint requests to 1516-233 Kennedy Street, Winnipeg R3C 3J5, Canada.
Clinical reports on the integrity of the corneal reflex after contralateral hemisphere lesions are contradictory. Grinker (1937), Oliver (1952), Monrad-Krohn (1964) and Ross (1972) all suggest that a deep parietal lobe lesion abolishes the reflex.

Gardner (1933) removed a hemisphere, leaving the basal ganglia intact, and abolished the opposite corneal reflex. Walker (1940) had the same findings, and in another patient reported an absent opposite corneal reflex in association with a convexity, centroparietal, meningioma. On the other hand, Ross (1972) reported normal corneal reflexes in several patients with superficial, convexity lesions. Zollinger's report (1935) agrees with those of Gardner and Walker.

Conversely, Dandy (1973) reported a small series of patients in whom one hemisphere had been removed. His first and second patient retained both corneal reflexes postoperatively. Troost, Weber and Daroff (1972) studied hemispheric control of eye movements in a patient who had a hemispherectomy eleven years earlier, leaving the basal ganglia intact. His corneal reflexes were present and equal.

The consensus of these divergent opinions seems to be that any type of hemisphere lesion may temporarily interfere with the opposite corneal reflex. Long term abolition is least likely with a cortical or superficial lesion, whereas thalamic lesions are more likely to produce permanent loss.

In an attempt to futher elucidate the supranuclear pathway of the corneal reflex, a number of cats have been subjected to various destructive lesions of one cerebral hemisphere. Their corneal reflexes, plus their electrically evoked, supra orbital reflexes were examined pre and postoperatively.

\section{METHODS}

Mature, domestic cats of either sex were used. In this study corneal reflex means closure of the eye in response to touching the cornea. Supra orbital reflex means the electrical and clinical response of the orbicularis oculi muscle to electrical stimulation of the supra orbital nerve. All reflex testing was done with the animal alert and without the appearance of the third eyelid covering the infero-medial part of the eye. When this eyelid was visible the animals were generally soporific and unresponsive. The supra orbital nerve was stimulated percutaneously with the cathode at the supra orbital foramen. Responses were recorded with surface electrodes from the orbicularis oculi muscle. The reference elec- 
trode was placed on the nasion and the tail was grounded. Action potentials were displayed on an oscilloscope after amplification and photographed by a Polaroid camera.

Destructive lesions of the thalamus were produced by electrocoagulation using stereotactic coordinates as delineated by Snider and Niemer (1961).

\section{RESULTS}

A four kilogram mature male cat (No. 2) was anaesthestised with intraperitoneal nembutal. A left frontal bone flap was removed. A vertical amputation of the frontal pole of the left hemisphere at the approximate stereotactic coordinate A22 was carried out. This is at the posterior end of the coronal gyrus.

Examination on the fourth post-operative day showed the right foreleg held in extension and the forefoot slipping out from under the animal, either forward or to the side, as he walked. Claw abduction and adduction, in pleasurable situations was absent in the right forefoot, present on the left. The right hind leg was normal. The left ear responded to tickling, the right did not.

Touching the left cornea produced immediate blinking. Touching the right produced variable results. If the stimulus was light and of short duration there was either no blink or a blink after a long latency. The difference between the two sides proved to be short lived. Examination on the seventh post-operative day showed the same extensor paresis of the right foreleg, absence of claw abduction, etc., and no right ear response to tickle. Corneal reflexes on this day were normal and identical and remained this way. On the nineteenth post-operative day and on several subsequent days, supra orbital nerve stimulation was carried out and the reflex responses recorded from the orbicularis oculi muscle. The first and second responses on the two sides were identical as to amplitude, latency and duration. (Fig. 1)

An immature male cat (No. 3) weighing two and a half kilograms was anaesthetised as above. After removing a left central bone flap, the entire left cerebral hemisphere was taken out leaving the basal ganglia intact. On the fourth postoperative day the animal was walking with some stiffness and awkwardness of the right limbs. A right homonymous hemianopsia was probably present. If left alone, the animal walked in a circle to its left, "looking over the left shoulder."

On the first two and possibly three, daily post-operative examinations there were some minor differences in corneal response. Touching the right cornea always evoked a response, but it was slower than the left. From the sixth post-operative day and onward, the corneal reflexes were identical. On the tenth post-operative day, when the wound was well healed and on several subsequent days, supra orbital nerve stimulation was carried out on both sides. The first and second responses were identical as to amplitude, latency and duration.

A mature male cat (No. 4) weighing three and a third kilograms was anaesthetised in the usual way. A left mid-central bone flap was removed. Using stereotactic coordinates as described by Snider and Niemer (1961) the thalamus was electrocoagulated at the following settings: Anteroposterior settings were at A7.5, A8.5, A9.5. Lateral settings at each of these positions were L1 to L8, inclusive. Vertical settings were $\mathrm{H}-1$ to $\mathrm{H}+7$, inclusive. The electrodes were four stainless steel wires in line in the coronal plane. The distance from the most medial to the most lateral electrode was $8 \mathrm{~mm}$. At each anteroposterior position, thirty milliamps of current was applied to the four electrodes for ninety seconds at three different depths, starting at $\mathrm{H}-1$ and ending at $\mathrm{H}+7$.

Immediately post-operatively, there was some delay in blinking if the right cornea was touched. By the third post-operative day the corneal reflexes were normal and equal on the two sides. Ten days post-operatively, supra orbital nerve stimulation evoked a primary and secondary response that was identical right and left.

Forty-eight days after the initial thalamus cautery, the animal was again anaesthetised and further destruction of the thalamus was carried out. Stereotactic coordinates were: anteroposterior, A10.5, A11.5, and A12.5. Vertical settings were $\mathrm{H}-1, \mathrm{H}+2$, and $\mathrm{H}+4$. The lateral dimensions of the lesion were $\mathrm{L} 1$ to $\mathrm{L} 5.32$ at a depth of $\mathrm{H}-1$, $\mathrm{L} 1$ to $\mathrm{L} 8$ at a depth of $\mathrm{H}+2$ and L1 to L5.32 at a depth of $\mathrm{H}+4$. At each depth, at each anteroposterior position,

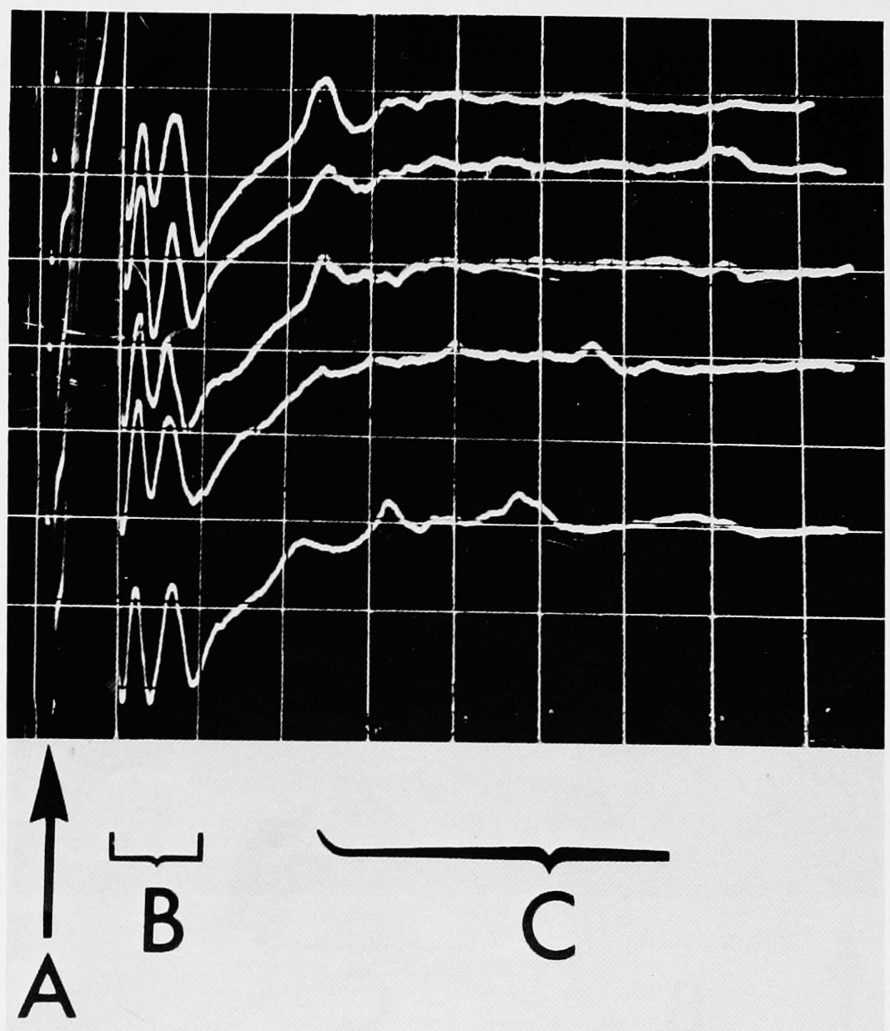

Figure 1-Cat No. 2. Supraorbital nerve stimulation 3 weeks after left cerebral frontal pole amputation. All shocks at 14 milliamps for 0.1 milliseconds, applied at A. First reflex response at $\mathrm{B}$ and second at $\mathrm{C}$. Top two traces recording from the left orbicularis oculi and bottom three from the right. (Stimulus was always ipsilateral to the recording side.) Calibration $0.5 \mathrm{mv}$ and $5 \mathrm{msec}$ per division. 
thirty milliamps of current was applied for ninety seconds.

Examination four days post-operatively showed the animal walking in circles to his left. There appeared to be a right homonymous hemianopsia. The left corneal reflex was present and normal. A light touch on the right cornea produced no blink of either eye. By the ninth post-operative day the difference in the two sides was gone and the two reflexes were clinically identical. Supra orbital nerve stimulation at a variety of current strengths on several days always produced a primary and secondary reflex response on the left side and only a primary response on the right (Fig. $2 \mathrm{~A}$ and $\mathrm{B}$ ). The extent of the thalamic lesion is shown in Fig. 3 A, B, C and D.

A five kilogram mature male cat (Cat No. 5) was anaesthetised in the usual way. A left central bone flap was removed and the thalamus was cauterised. Stereotactic coordinates were as follows: Anteroposterior settings were A10.5, A11.5, and A12.5. Vertical positions were $\mathrm{H}-1, \mathrm{H}+2$, and $\mathrm{H}+4$. The lateral dimensions of the lesion were L1 to L8 at settings A11.5 and L1 to L5.32 at A10.5 and A12.5. The lateral dimensions were the same at all three depths. At each depth, at each anteroposterior position, thirty milliamps of current was applied for ninety seconds.

Twenty-four hours post-operatively the animal was on his feet and fit to be examined. The left pupil was twice as big as the right and remained this way for several days. Both reacted briskly to light. Spontaneous blinks were often seen in the left eye only. A coarse stimulus to either cornea produced a blink. A light stimulus to the left cornea always provoked a blink while sometimes it did not when applied to the right cornea.

Three days post-operatively, the cat was walking in circles to his left with an apparent right hemianopsia and a spastic right foreleg. Pupil size and spontaneous blinking were the same in the two eyes, and a coarse or fine stimulus produced an identical blink when applied to either cornea.

Supra orbital nerve stimulation was carried out preoperatively (Fig. $4 \mathrm{~A}$ and $\mathrm{B}$ ) and on the fifth, ninth and seventeenth post-operative days (Fig. $5 \mathrm{~A}$ and $\mathrm{B}$ ). The first and second reflex responses were present each time from both sides.

The extent of the thalamic lesion in this animal can be seen in Fig. 6
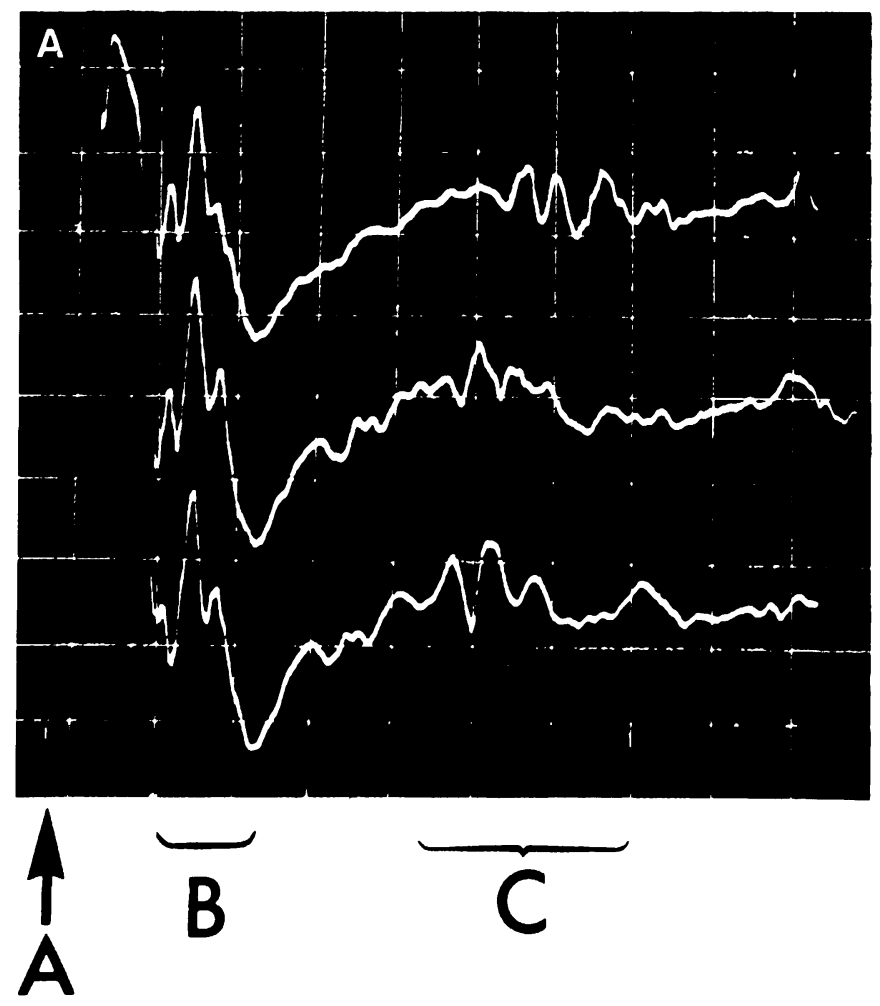

Figure 2A-Cat No. 4. Left Supraorbital nerve stimulation and left orbicularis oculi recording after left thalamus cautery. Stimulus of 10 mamp for $0.1 \mathrm{msec}$ applied at A. First reflex response at $\mathrm{B}$, second at $\mathrm{C}$. Calibration $0.5 \mathrm{mv}$ and $5 \mathrm{msec}$ per division.

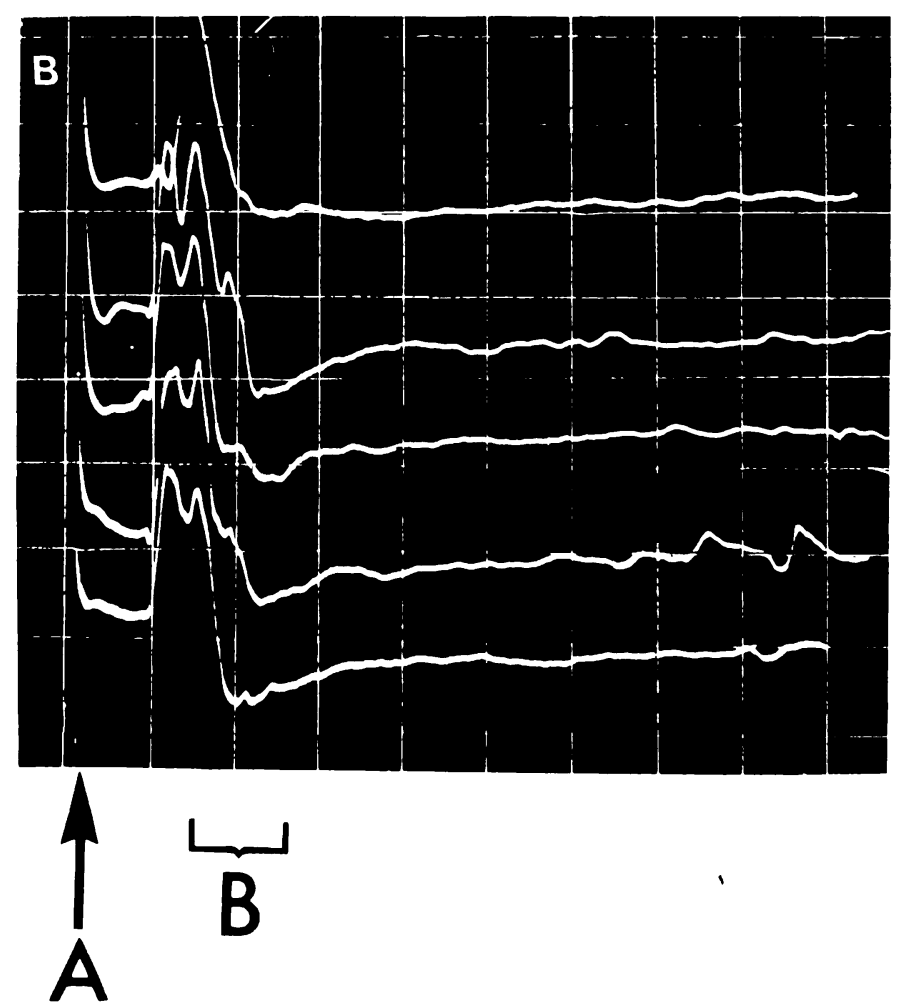

Figure 2B-Cat No. 4. Right supraorbital nerve stimulation and right orbicularis oculi recording after left thalamus cautery. Shock applied at A, first reflex response at B and no second response. Stimulus, 10 mamps for $0.1 \mathrm{msec}$. Calibration 0.5 $\mathrm{mv}$. and $5 \mathrm{msec}$ per division. 


\section{DISCUSSION}

Reflex blinking has been studied by many. Various stimuli have been used. These include tapping of the brow, Kugelberg (1952), a fine jet of saline on the cornea, Thatcher and Van Allen (1971), a flash of light, noise, glabellar tap and electrical stimulation of the supra orbital nerve, Rushworth (1962), Kimura, Powers \& Van Allen (1969), Kimura (1970), and Kimura, Rodnitzky and Van Allen (1970). From these studies it is evident that electrical stimulation of the peripheral branches of the trigeminal nerve can evoke action potentials from all the mus-

A

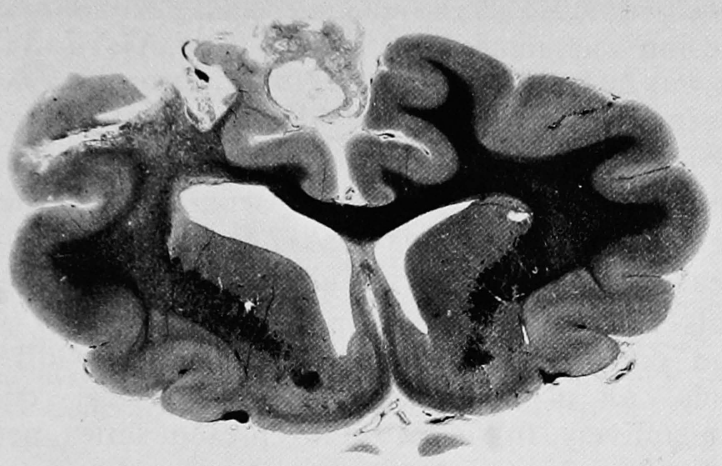

IMETRIC,
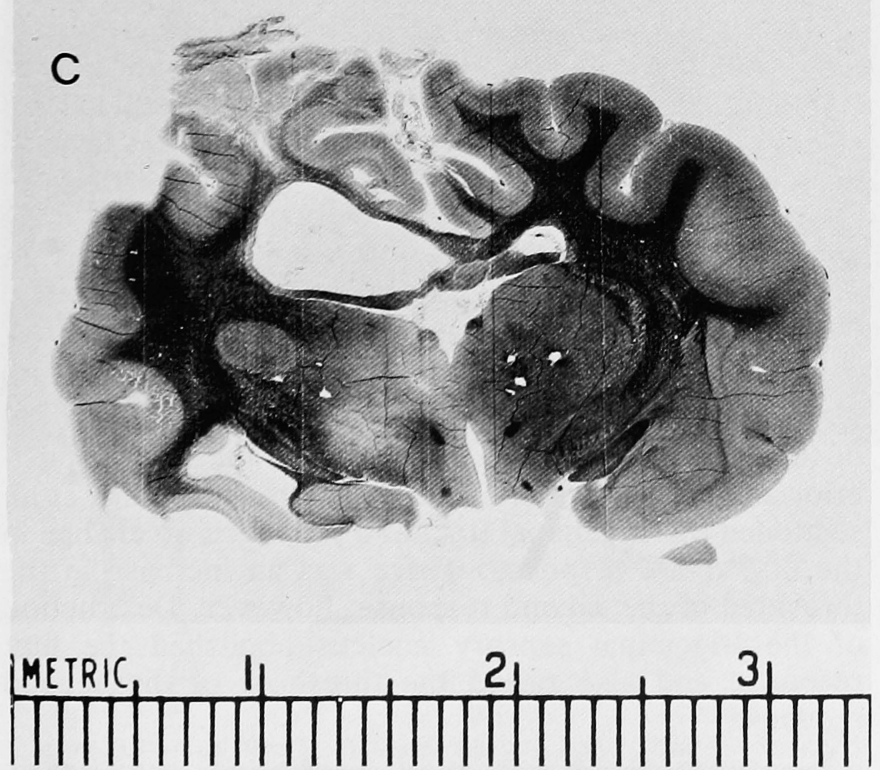

cles supplied by the facial nerve. Two kinds of reflex response have been observed following stimulation of the supra orbital nerve. The first response has a latency between 8.0 and 12.0 milliseconds and a duration of 5-10 milliseconds. It is exclusively unilateral. The second response has a latency of 20 to 30 milliseconds, a duration of 10-20 milliseconds and is always bilateral. The stimulus threshold of the second response is higher than the first. These two reflexes are separate contractile responses in the orbicularis oculi muscle and are similar to the responses evoked from a glabellar tap except the
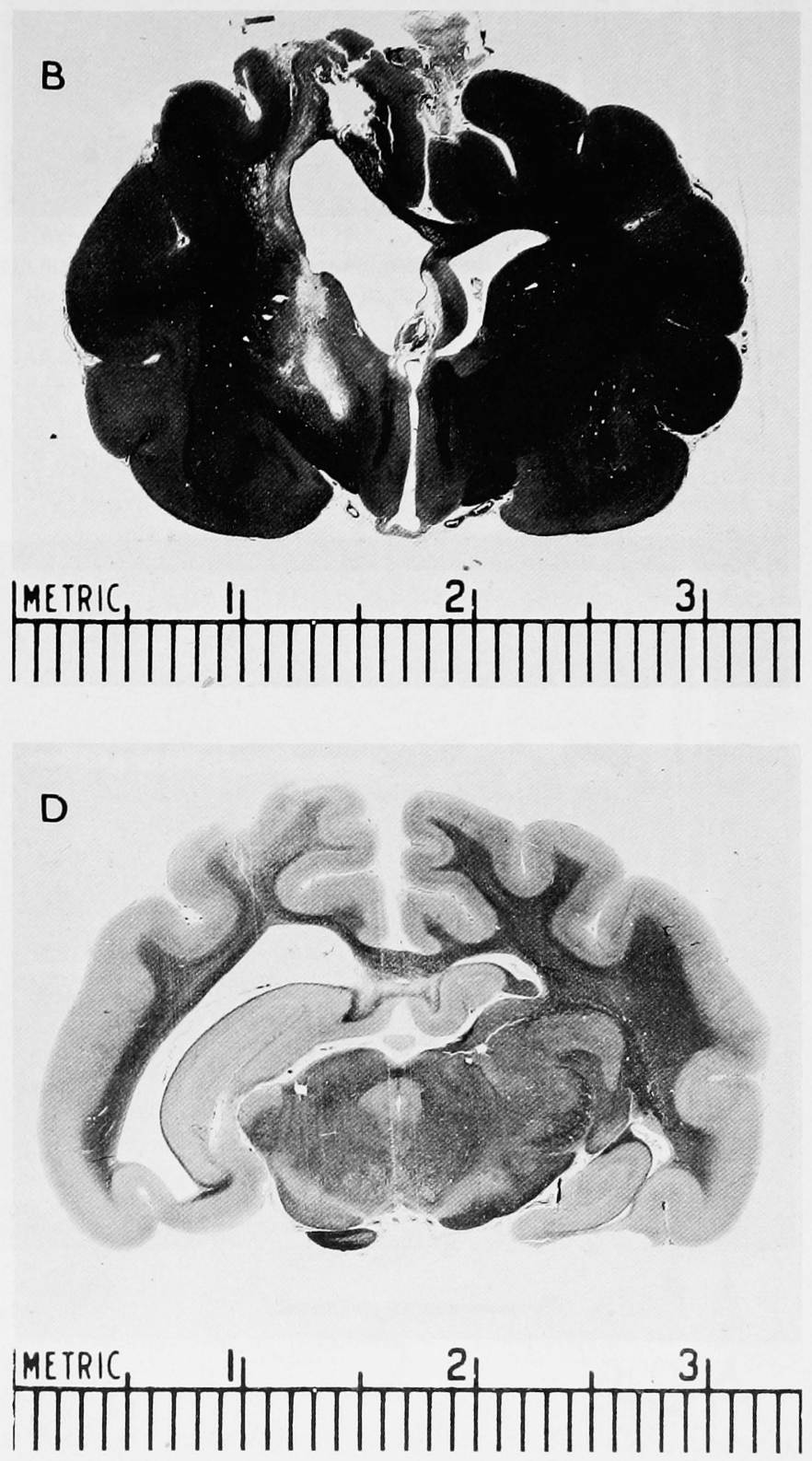

Figure 3-Coronal sections of brain of cat No. 4-destruction of left thalamus. 3A is at approximate stereotactic position A20; $3 \mathrm{~B}$ is at approximate position A13.5; $3 \mathrm{C}$ is at approximate position A10, and $3 \mathrm{D}$ is at A5. 


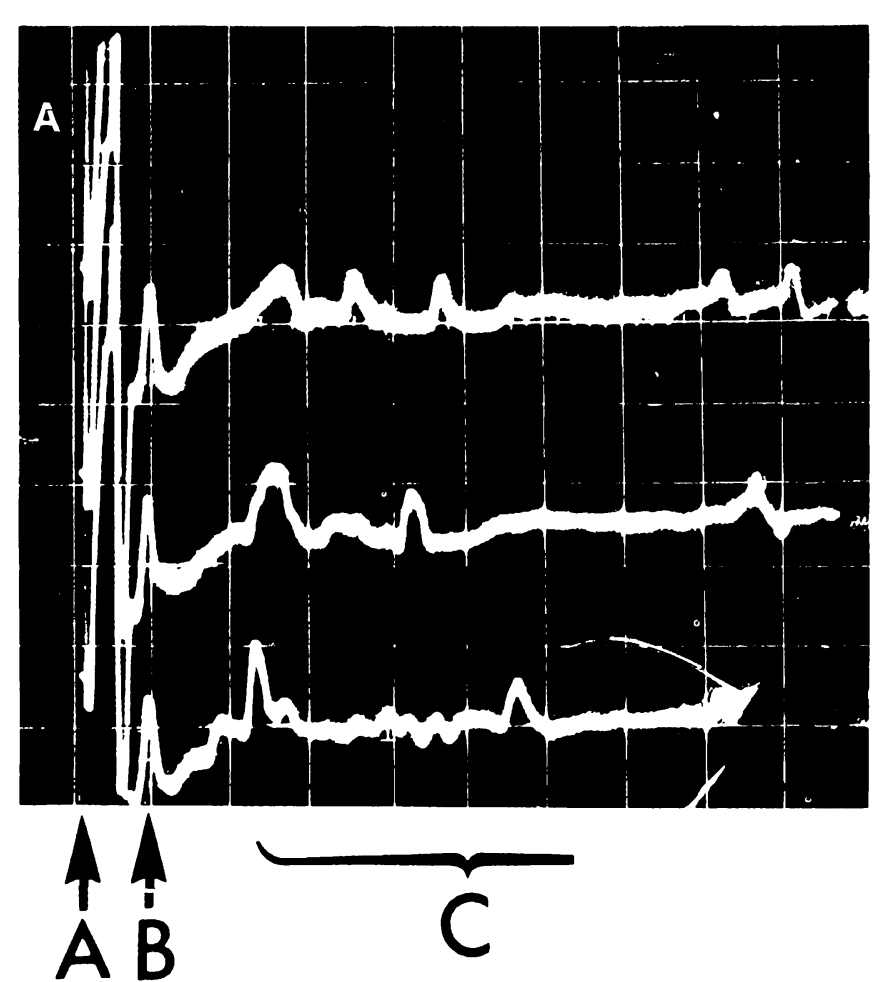

Figure $4 A-$ Cat No. 5. Pre-operative left supraorbital nerve stimulation and recording from left oebicularis oculi. Shocks at A. at 34 mamps for 0.1 msecs. First reflex response at B and second at $\mathrm{C}$. Calibration $5 \mathrm{mv}$. and $10 \mathrm{msecs}$ per division.
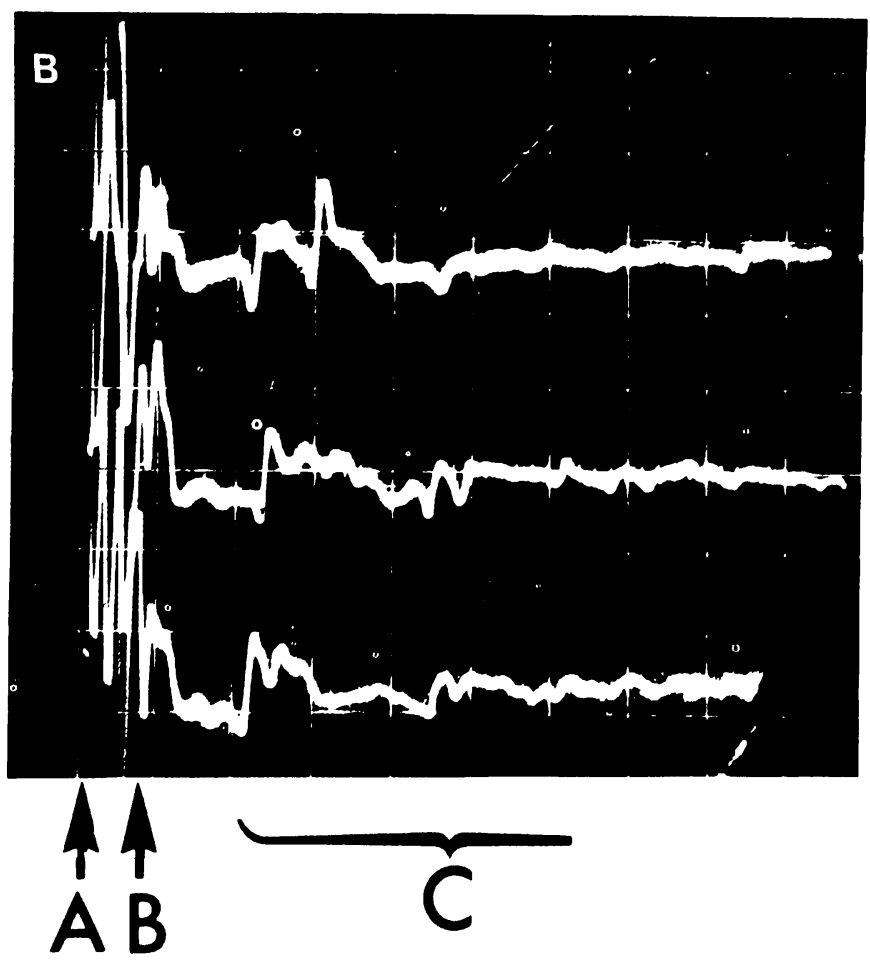

Figure $4 B-$-Cat No. 5. Pre-operative right supraorbital nerve stimulation and right orbicularis oculi recording. Shocks at A, 23 mamps for $0.1 \mathrm{msecs}$, first reflex response at $\mathrm{B}$, and second at C. Calibration $5 \mathrm{mv}$. and $10 \mathrm{msecs}$ per division. latencies are about 4 milliseconds shorter. Blinking evoked by touching the cornea is accompanied by the second reflex response only, Kugelberg (1952).

All the cats reported here were examined pre- and post-operatively. All had first and second reflex response from supra orbital nerve stimulation pre-operatively. All had active corneal reflexes pre-operatively. It was not possible to abolish the corneal reflex for more than a few days after a destructive operation on the opposite hemisphere. These operations included partial and total hemispherectomy and partial and total destruction of the thalamus.

However, when the entire thalamus was destroyed, the contralateral second reflex response disappeared permanently. Cat No. 4 was first subjected to a partial destruction of the thalamus (stereotactic settings A7.5 to A9.5) with no permanent change in either the corneal reflex or the supra orbital nerve stimulation, blink reflex. When the lesion was enlarged to extend from A7.5 to A12.5, there was no permanent change in the corneal reflex, but the second reflex response could not be elicited (Fig. $2 \mathrm{~A}$ and B).

Similarly, cat No. 5 with a partial thalamic lesion (stereotactic setting A10.5 to A12.5) maintained both a corneal reflex and both first and second reflex response.

Walker and Fulton (1938) performed local and widespread cortical extirpations in a group of different animals. All of these retained their corneal reflexes postoperatively. In the cats in this present series, neither the corneal reflex, or the first or second reflex response was disturbed by this type of destructive procedure.

The central pathway of the supra orbital reflex has been studied in the cat by Tokunaga, Oka, Murao, Okumura, Hirata, Migaslita, and Yoshitatsu (1958). Like Walker and Fulton, they found no change in either first or second reflex response after selective destruction of the cortical, facial motor area. No change was evident after unilateral transection through the subcortex, or through the anterior part of the thalamus. Further, they selectively destroyed the anterior medial and lateral nucleus of the thalamus with no change in either response. Lesions of the ventral thalamic nucleus abolished the second response. In the present series it was necessary to destroy the whole thalamus to achieve the same result.

McKinley and Magoun (1942) and Berry, Anderson and Books (1956) also suggested that the central pathway of the corneal reflex was connected to the ventral posterior and medial nuclei of the thalamus. Tokunaga et al. sectioned the trigeminal tract and produced no change in the first reflex response. There was an increase in the threshold of the second response, however. Destruction of the trigeminal sensory nucleus abolished the first response and also raised the threshold of the second response.

In another animal they sectioned the hemidiencephalon at the level of the superior colliculus and abolished the contralateral second reflex response. First 


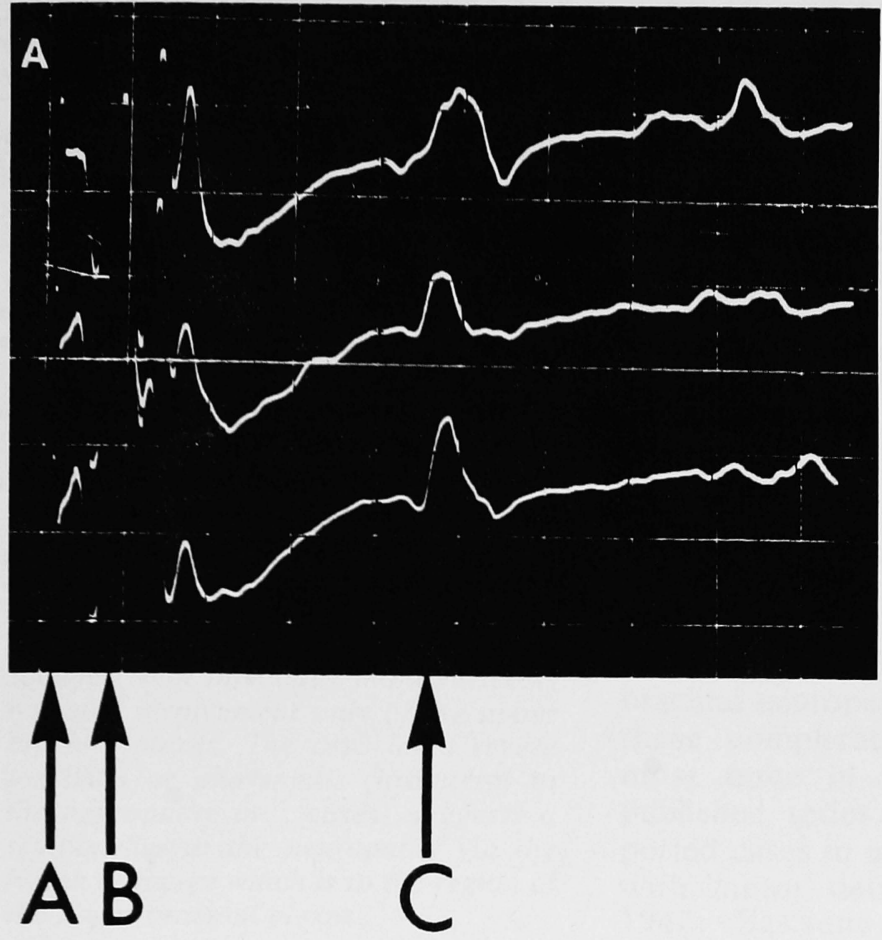

Figure 5A-Cat No. 5. Post-operative, left sided supraorbital nerve stimulation at $A$ at 35 mamps for 0.1 msecs. Left orbicularis oculi recording. First reflex response at B, second at C. Calibration, $5 \mathrm{mv}$ and $5 \mathrm{msec}$ per division.
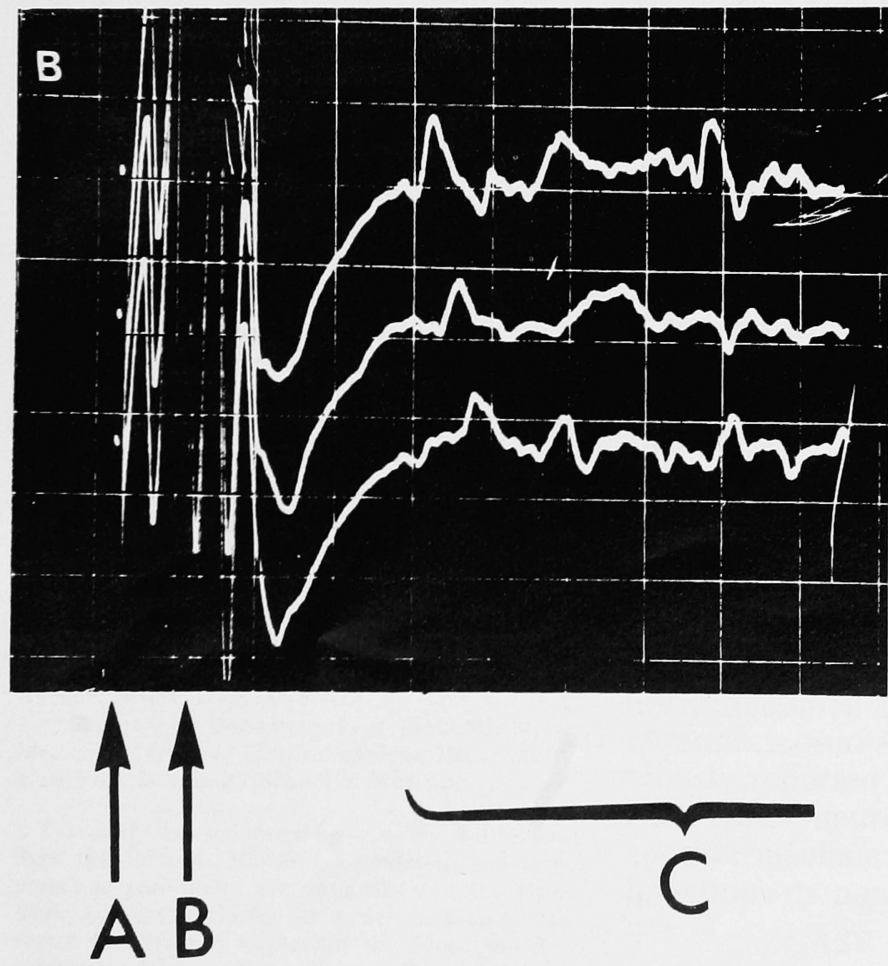

Figure 5B-Cat No. 5. Post-operative, right sided supraorbital nerve stimulation at $\mathrm{A}, 30 \mathrm{mamp}$ for $0.1 \mathrm{msec}$ and right orbicularis oculi recording. First reflex response at $\mathrm{B}$, and second at $\mathrm{C}$. Calibration $5 \mathrm{mv}$ and $5 \mathrm{msec}$ per division. reflex responses persisted on both sides as well as the ipsilateral second response. This was also true after hemi transection of the midbrain. A transection through the pons at the level of the facial nucleus abolished both reflexes on the operative side with no change in either contralateral response.

Walker (1942) also observed the disappearance of the corneal reflex after contralateral mesencephalic trigeminal tractotomy.

\section{ACKNOWLEDGEMENTS}

Professor J. W. Phillis of the Department of Physiology and Dr. Larry Jordon provided space, animals, equipment and advice and without them, this work would not have been possible. Dr. Nasser Shojania of the Department of Pathology did the histology. We are very grateful to them all.

\section{REFERENCES}

BERRY, C. M., ANDERSON, F. D., and BOOKS, D. C. (1956). Ascending pathways of the trigeminal nerve in the cat. Journal of Neurophysiology, 19, 144-151

DANDY, W. E. (1933). Physiological Studies following extirpation of the right cerebral hemisphere in man. Bulletin of the Johns Hopkins Hospital, 53, 31-41.

GARDNER, W. J. (1933). Removal of the right cerebral hemisphere for infiltration glioma. Journal of the American Medical Association, 101, 823-826.

GRINKER, R. F. (1937). Neurology. Charles E. Thomas; Springfield. KIMURA, JUN., POWERS, J. MICHAEL., .VAN ALLEN, MAURICE W. (1969). Reflex response of orbicularis oculi muscle to supraorbital nerve stimulation. Archives of Neurology, 21, 193-199.

KIMURA, JUN., RODNITSKY, ROBERT L., VAN ALLEN, MAURICE W. (1970). Electrodiagnostic study of trigeminal nerve. Neurology, 20, 574-583.

KIMURA, JUN. (1970). Alterations of the orbicularis oculi reflex by pontine lesions. Archives of Neurology, 22, 156-161.

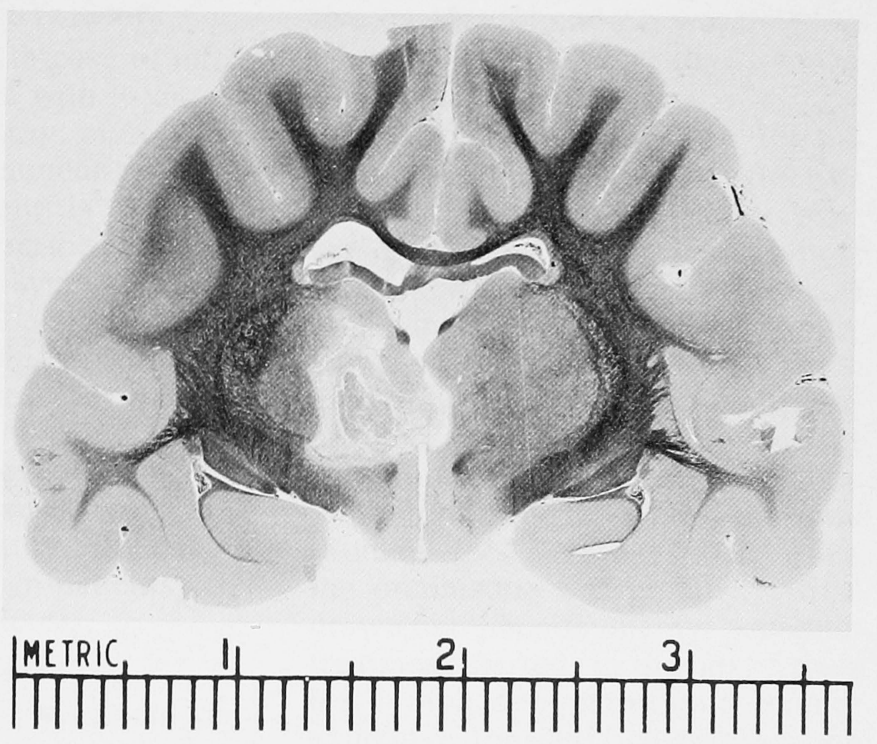

Figure 6-Representative coronal section of brain of cat No. 5 at approximate stereotactic coordinate A 10.5, 45 days postoperative. Partial destruction of the left thalamus. 
KUGELBERG, E. (1952). Facial Reflexes. Brain, 75, 385-396.

McKINLEY, W. A., MAGOUN, H. W. (1942). The bulbar projection of the trigeminal nerve. American Journal of Physiology, 137, 217-226.

MONRAD-KROHN, G. H. (1964). Clinical Examination of the nervous system. P. 207, Lewis; London.

OLIVER, L. C. (1952). The supranuclear arc of the corneal reflex. Acta Psychiatrica Scandinavica, 27, 329-333.

ROSS, R. T. (1972). Corneal Reflex in Hemisphere Disease. Journal of Neurology, Neurosurgery and Psychiatry, 35, 877-880.

RUSHWORTH, GEOFFREY (1962). Observations on blink reflexes. Journal of Neurology, Neurosurgery and Psychiatry, 25, 93-107.

SNIDER, RAY S., NIEMER, WILLIAM T. (1961). A stereotaxic atlas of the cat brain. University of Chicago Press; Chicago.

THA TCHER, D. B., and VAN ALLEN, M. W. (1971). Corneal reflex latency. Neurology, 21, 735-737.
TOKUNAGA, A., OKA, M., MURAO, H., YOKOI, T., OKUMURA T., HIRATA, T., MIYASHITA, Y., YOSHITATSU, S. (1958). An experimental study on facial reflex by evoked electromyography. Medical Journal of Osaka University, 9, 397-411.

TROOST, B. TODD., WEBBER, RONALD B., DAROFF, ROBERT B. (1972). Hemispheric control of eye movements. Archives of Neurology, 27, 441-448. (Information on corneal reflexes was not included in the paper but provided courtesy of Dr. Daroff as a personal communication.)

WALKER, A. E., and FULTON, J. F. (1938). Hemidecortication in chimpanzee, baboon, macaque, potto, cat and coati. Journal of Nervous and Mental Diseases, 87, 677-689.

WALKER, A. E. (1940). The cerebral arc of the corneal reflex. Journal of Nervous and Mental Diseases, 92, 569-578.

WALKER, A. E. (1942). A method for the relief of unilateral intractable pain. Archives of Surgery, 44, 953-962.

ZOLLINGER, R. (1935). Removal of the left cerebral hemisphere. Archives of Neurology and Psychiatry, 34, 1055-1066. 